Daimon. Revista Internacional de Filosofía, Suplemento $n^{\circ} 7$ (2018), pp. 191-206

ISSN: 1130-0507 (papel) y 1989-4651 (electrónico)

http://dx.doi.org/10.6018/daimon/333791

\title{
¿Fraternidad política con los animales? Hacia una justicia interespecífica
}

\author{
Political fraternity with animals? \\ Towards an interspecific justice*
}

CRISTIAN MOYANO FERNÁNDEZ**

\begin{abstract}
Resumen: En este artículo se ofrecerán tres razones a fin de defender una fraternidad política con los animales. La primera comprenderá a los animales como miembros de la misma clase social oprimida que los humanos durante el desarrollo capitalista. La segunda analizará el concepto de ciudadanía matizando su rasgo de participación política y resaltando el rasgo de compartir un espacio común. La tercera introducirá el dinamismo orgánico y ecológico en el espacio de convivencia. Finalmente, mediante una relativización del concepto de vulnerabilidad, se concluirá que nuestra relación política con los animales no ha de ser siempre paternalista, hospitalaria o solidaria, sino también fraternal.

Palabras clave: animales no humanos; fraternidad; clase social; ciudadanía; interdependencia; vulnerabilidad.
\end{abstract}

\begin{abstract}
In this paper three reasons will be given in order to defend a political fraternity with animals. First, animals will be considered as members of the same oppressed social class like humans during capitalist development. Second, the concept of citizenship will be analyzed refining its political participation feature and highlighting the trait of sharing a common space. Third, an organic and ecological dynamism will be introduced in the space of coexistence. Finally, through a relativization of the concept of vulnerability, it will be concluded that our political relationship with animals should not be always paternalistic, hospitable or solidary, but also fraternal.
\end{abstract}

Keywords: non-human animals; fraternity; social class; citizenship; interdependence; vulnerability.

\section{Introducción}

Este artículo no pretende defender una fraternidad política con los animales a ultranza, de igual modo que no hay consenso unívoco sobre la necesidad de una fraternidad universal entre seres humanos. La fraternidad política, más allá de su sentido cristiano de «hijos de un

Recibido: 07/06/2018. Aceptado: 02/07/2018.

* Este trabajo se enmarca en el proyecto de investigación «Justicia y democracia: hacia un nuevo modelo de solidaridad», con código FFI2015-64858-P, financiado por el Ministerio de España.

** Investigador en formación y doctorando del Departamento de Filosofía de la Universidad Autónoma de Barcelona (UAB). Líneas de investigación: bioética; teorías de la justicia; salud pública; ética animal; ecologismo; ética alimentaria. Publicaciones recientes: «¿Alimentarnos libremente o por igual? Solidaridad e identidad» en la Revista de Bioética y Derecho, ${ }^{\circ}$ 42, 2018. «Identity or solidarity food: ex-ante responsibility as a fair culture approach» en Springer, S. y Grimm, H. (eds.), Professionals in food chains, EurSafe Conference Proceedings, Wageningen Academic Publishers, 2018.Contacto: cristian.moyano@uab.cat 
mismo padre», trataba de respaldar los esfuerzos de la clase trabajadora, los descamisados, por emanciparse durante la Revolución francesa. Este valor propugnado por Robespierre iba dirigido a un grupo oprimido que no tenía los mismos derechos que los estamentos favorecidos por la jerarquía feudal, a fin de hermanarse y luchar por una causa común: la realización autónoma que no había logrado el derecho de igualdad o el de libertad. Su reclamo y exigencia fue útil para un reconocimiento político más justo. Pero de su función como dispositivo que encendiera y catalizase los derechos de los individuos más oprimidos, no tenía por qué inferirse un sentimiento fraternal en un sentido familiar o privado, sino que su implicación iba encarada a la esfera pública. Servía para estimular a ensanchar el círculo de la moral, no para centrarse tanto en la afección fraterna como en el respeto político fraterno (aunque no significa que ambas derivas de la moral sean plenamente independientes).

Del mismo modo, reflexionar sobre una fraternidad política con los animales aquí nos sirve para estimular a la moral y a la política para dedicar mayor atención a los derechos de los seres vivos no humanos. Unos derechos que no tienen por qué predicarse de forma totalmente justificada si se parte de un discurso basado en la libertad, en la igualdad o en la solidaridad. Entiendo, aquí, que la fraternidad es una idea que puede complementar los clásicos debates acerca de los derechos de los animales no eclipsando el resto de valores, sino sumando otro enfoque prolífico. Para ello, ofreceré tres razones. La primera se sustentará en la historia del desarrollo del capitalismo para comprender a los animales como miembros de la misma clase social oprimida que los humanos. La segunda consistirá en analizar el concepto de ciudadanía matizando su rasgo de participación política y reconduciendo la asignación de tal condición hacia la característica de compartir un espacio común. La última complementará a la segunda al introducir el dinamismo orgánico y los tiempos ecológicos en el espacio de convivencia, dando cuenta de las acciones que ligan a los distintos individuos en un continuum vital. Planteadas estas consideraciones que nos acercan a los animales en un sentido triple, concluiré que nuestra relación política con ellos no ha de ser en todo caso paternalista o basada en lazos de hospitalidad o solidaridad, como varios autores sostienen, sino que es preciso construirla sobre la fraternidad. Sobre este último punto, apuntaré la urgencia de atender al carácter de la vulnerabilidad, pero criticando el trato meramente asistencial que la reduce a una cualidad individual en lugar de estructural. El tipo de fraternidad, tal y como la presentaré, exige una consiliencia que reúna una comprensión interdisciplinar.

\section{La clase social invisible de los animales}

A todos los miembros del pueblo llano del siglo XVIII no les unían lazos de sangre, del mismo modo que con todos los animales no formamos una familia en sentido consanguíneo. Lo que unía a los campesinos, artesanos y descamisados era una clase social explotada. Unas condiciones de opresión ante las que querían resistirse y, en ocasiones, sublevarse. Una situación de trabajo exhaustivo y maltrato similar a la que padecían los animales que se empleaban para labrar los campos, allanar caminos, producir más alimentos, lanas y otras mercancías, o transportar personas y objetos. Sin embargo, mientras los individuos del estamento más bajo de la sociedad hicieron de su situación de injusticia una causa común de resistencia y emancipación, los animales quedaron al margen. 
La reivindicación proclamada por los sans-culottes de unos derechos políticos auténticamente iguales a los del resto de la sociedad francesa, explotó con la Revolución de 1789. Pedían libertades e igualdad, pero lo que les ayudó a alzarse por su consigna de justicia fue la fraternidad exigida por Robespierre ${ }^{1}$. El grito que ataba un lazo a la distinción entre loi de civil y loi de famille de Montesquieu logró la calurosa acogida de los numerosos plebeyos demócratas que lidiaban por la emancipación de cualquier dependencia con su señor feudal para poder subsistir. "Emanciparse" pasó a ser sinónimo de "hermanarse", lo que levantó una conciencia política generalizada de que los trabajadores dejaban de estar subyugados a todo señor o patriarca para únicamente aceptar como progenitor a la nación o la patria. Por fin, en la Francia de la época las exigencias de la libertad e igualdad conseguían su unificación gracias a la fraternidad, que rompía con el despotismo patriarcal.

«Los individuos no son ciudadanos porque sean hermanos o hijos naturales de una misma madre o nación y de un mismo padre o patria. Son hermanos, políticamente hablando, porque, al pertenecer a una nación y una patria, son ciudadanos. La patria ya no es la tierra de los padres, como en la antigua Grecia, sino el espacio privilegiado de la libertad y la igualdad» ${ }^{2}$.

Esta conciencia de clase surgida ante la pretensión de insubordinación civil y abolición de la ley de familia ayudaría a fertilizar buena parte de las ideas socialistas que irrumpirían políticamente en 1848. La historia hegemónica nos cuenta que la fuerza que se opuso al crecimiento del capitalismo y de las desigualdades durante las revoluciones industriales parece fraguada exclusivamente por los seres humanos trabajadores. No obstante, obviar la participación de los animales en este motor revolucionario es una visión parcial de la historia política.

Curiosamente, los movimientos en defensa de los derechos de los animales se dispararon desde finales del siglo XVIII, a raíz de importantes escritos que se enfocaban en la compasión o en evitar el dolor innecesario ${ }^{3}$, y de autores anglojacobinos que inspirados por la Revolución francesa defendieron las semejanzas entre los oprimidos del Tercer estado y los animales. Como asevera el historiador Jason Hribal: «su éxito se demostró con la publicación de tres libros trascendentales: The Cry of Nature: An Appeal to Mercy and to Justice on Behalf of the Persecuted Animals (1791), de John Oswald; On the Conduct of Man to Inferior Animals (1797), de George Nicholson y An Essay on Abstinence from Animal Food (1802), de Jospeh Ritson» ${ }^{4}$.

A principios del siglo XIX la promoción de la lástima y la compasión fue insuficiente y las negociaciones de la moral tuvieron que ceder el paso a unas negociaciones políticas. Surgieron las demandas de unos derechos políticos que protegieran legalmente a los "animales irracionales". Y en 1822 el Parlamento británico promulgó la primera ley contra el maltrato animal, aplicada a aquellos domésticos y de propiedad, como caballos, burros y ganado ${ }^{5}$.

1 Domènech, A. (2004), El eclipse de la fraternidad, Barcelona: Crítica, p. 83.

2 Puyol, A. (2017), El derecho a la fraternidad, Madrid: Catarata, p. 31.

3 Bentham, J. (1982), An Introduction to the Principles of Morals and Legislation, London: Methuen.

4 Hribal, J. (2014), Los animales son parte de la clase trabajadora, Madrid: Ochodoscuatro, pp. 89-90.

5 Singer, P. (2011), Liberación animal, Madrid: Taurus. 
Pero aun con la aparición de los primeros derechos, que los animales pudieran ser considerados nuestros hermanos, en tanto miembros de la misma clase social que los campesinos, artesanos y proletariado de la época no era una aceptación fácil. Karl Marx negaba esta idea, amparándose en que sólo los hombres modificaban y manufacturaban con una visión y creatividad de la que los demás animales carecían. La función de los animales respondía a los planes y propósitos humanos, mientras que el trabajo sólo podía ser «una característica exclusivamente humana» ${ }^{6}$. Así, para Marx, los animales eran meros instrumentos, mercancías y formas de capital circulante. Anteriormente, Adam Smith sí que había considerado a los animales como equivalentes a los humanos en lo respectivo a la fuerza del trabajo. Para el economista escocés, ambas especies producían más que un valor económico, generaban plusvalía y, en ese sentido, ambos eran trabajadores ${ }^{7}$. ¿Qué punto de vista parece más acertado y qué implicación puede tener la aceptación de uno u otro?

El historiador Jason Hribal defiende la tesis de que los animales trabajadores han cumplido una función clave en el desarrollo de la fuerza industrial ${ }^{8}$. No obstante, el sociólogo Bob Torres ve dos problemas con esta forma de pensar: la primera es que mientras los humanos ven una separación entre el hogar y el trabajo, los animales nunca lo hacen; y la segunda es que los animales no pueden resistir ante su explotación, carecen de voz y no pueden unirse, planear y luchar hasta provocar un cambio. Son dos críticas que Hribal no tarda en refutar. Primero, tal y como argumenta, el objetivo del capitalismo consiste en difuminar la separación entre vida y trabajo: los estudiantes hacen deberes en casa, bajo el patriarcado las mujeres son las encargadas de realizar las tareas domésticas, el trabajo se lleva desde la oficina al hogar, cada vez aparecen más negocios domésticos, etc. De manera que la primera objeción, bajo el prisma del mecanismo capitalista, señala más similitudes que diferencias entre animales y humanos. Segundo, los animales sí han mostrado resistencia ante el proceso productivo: moviéndose despacio a propósito, ignorando órdenes, pateando, mordiendo, saltando o escapando. No se puede ignorar que albergan una intencionalidad. De hecho, el mismo Marx reconocía que si la energía generada por los caballos era la peor de todas se debía en buena parte a que ellos tenías su propia cabeza9 No era que los animales no tuvieran voz, sino más bien que los estábamos silenciando, negando nuestras verdaderas relaciones de clase. La cualidad de agencia comúnmente se ha asignado como constitutiva a la especie humana, especialmente cuando se pretendía construir una identidad que denotase estatus y privilegios jurídicos. Aristóteles, por ejemplo, no concebía a los esclavos como agentes autónomos, sino que su agencia se desvanecía bajo la voluntad del amo, quien los usaba como instrumentos de producción, como su propiedad. Así, los esclavos no poseían razón ni capacidad de iniciativa, sino que era su naturaleza e instintos lo que les permitía reaccionar ante las normas despóticas dictadas por su $\mathrm{amo}^{10}$.

\footnotetext{
6 Marx, K. (1990), Capital, Nueva York: Penguin Classics, vol. 1, pp. 283-284.

7 Smith, A. (2011), La riqueza de las naciones, Madrid: Alianza.

8 Hribal, J., Los animales son parte de la clase trabajadora, op. cit.

9 Marx, K., Capital, p. 497, op. cit.

10 Aristóteles (2004), Política, Madrid: Tecnos, Libro I, cap. 4, pp. 123-126.
} 
Si en la antigua Grecia o en las colonias americanas el estatus jurídico de ser una propiedad invisibilizaba la agencia del individuo esclavizado, la industrialización impulsora de la globalización arraigó la estratificación de clases sociales que eclipsaría la posibilidad de una comunidad realmente libre e igualitaria. Pero la noción de hermandad encendió la chispa de varias revoluciones durante los últimos siglos, articulándose sobre la conciencia de formar parte de una misma clase social oprimida. Una fraternidad que no contó con los animales, a pesar de demostrar albergar esa conciencia de ser miembros de una colectividad explotada, ofreciendo una resistencia ante sus dominadores en numerosas ocasiones ${ }^{11}$. ¿Por qué entonces no se habla de extender la fraternidad política hacia ellos? A menudo se responde que los animales no pueden ser ciudadanos, presuponiendo que la asignación de tal condición es suficiente para dejar abierta la posibilidad de una fraternidad, y su ausencia justifica su exclusión. Pasemos a analizar esta cuestión de la ciudadanía.

\section{La ciudadanía invisible de los animales}

Los humanos no existimos al margen de la naturaleza, desconectados del mundo animal. Al contrario, a lo largo de la historia y en todas las culturas, hay una clara tendencia a entablar relaciones con animales. De hecho, en palabras del ambientólogo Paul Shepard, los animales «nos han hecho humanos» ${ }^{12}$. Así que prohibir relaciones de explotación con los animales no implica desligarnos de formas significativas de interacción con ellos, sino más bien reconocer la necesidad de promover unos derechos positivos relacionales que complementen a aquellos negativos.

Corine Pelluchon sostiene que no es fácil afirmar que los animales sean nuestros conciudadanos, ya que no sienten ni se consideran a sí mismos miembros de nuestra comunidad política. Y es que «la ciudadanía requiere que se tenga la percepción de un interés general que forma el espíritu de una comunidad, su identidad política y su constitución o politeia» ${ }^{13}$. Entonces sólo los humanos pueden ser plenamente los ciudadanos, los animales no: ellos son sujetos políticos. En tanto demuestran albergar intereses y preferencias individuales que comunican (a su manera) disponen de una agentividad fundamental para el reconocimiento político no extensiva a la condición de ciudadanos. Para Pelluchon, es el carácter de agencia lo que les permite formar parte del círculo de la justicia y que se les conceda unos derechos. De manera que los animales no son sólo pacientes morales, sino que son sujetos morales y políticos. ¿Pero en qué se distinguen los animales de las personas dependientes, como recién nacidos o discapacitados mentales, si a los primeros no se les considera ciudadanos pero a las segundas sí? Se insiste en que no debe confundirse su situación política. Un individuo humano puede ser considerado autónomo porque no vive de la misma manera la percepción de un trato desigual: los animales no sienten la injusticia de un modo colectivo, pero los humanos sí. Los seres humanos concebimos nuestra identidad asociándola a una comunidad que va más allá del círculo estrecho de los seres presentes o más allegados. Somos capaces

11 Una resistencia animal que se sumó a la humana y frenó, a veces, la perpetuación de la dominación y el avance del capitalismo. Los animales pueden considerarse agentes políticos. Véase Hribal, J., Los animales son parte de la clase trabajadora, op. cit.

12 Shepard, P. (1997), The Others: How Animals Made us Human, Washington DC: Island Press.

13 Pelluchon, C. (2018), Manifiesto animalista. Politizar la causa animal, Barcelona: Reservoir Books, p. 61. 
de preocuparnos por la suerte de seres que aún no han nacido, que viven lejos de nosotros o que son demasiado numerosos para que podamos representárnoslos y sentir empatía por ellos. Al ser capaces de proyectarnos en el tiempo y el espacio, a nuestra memoria histórica, desarrollamos una identidad con una cualidad diferente a la del animal: más temporal, más colectiva. Estos matices de la identidad humana nos brindan un modo de vivir la política especial, el modo de vivir propio del ciudadano.

Podemos estar más o menos de acuerdo con esta explicación de lo que implica ser un ciudadano. Pero es cierto que la forma de vida de los animales es distinta a la de los humanos por lo que respecta a la temporalidad: ellos viven en una dimensión unitaria del presente, nosotros linealmente desanclada del mismo ${ }^{14}$. Sin embargo, lo que no queda tan claro es que nosotros vivamos en un grado más extenso el sentimiento de comunidad y que presentemos una mayor inteligencia colectiva. De ser así, ¿tendría sentido que seamos la especie que más ha destruido su entorno ecológico en un tiempo evolutivo tan escaso? La memoria histórica y la empatía hacia las colectividades o las generaciones futuras motivada por la abstracción imaginativa, son dos mecanismos racionales de conectar con una suerte de cosmopolis. Pero que sean abstracciones resultantes de la proyección temporal propia del humano es una cosa, y otra que esta sea la única vía para sentir que se forma parte de una comunidad trascendente a los individuos más allegados de nuestro. Ciervos y elefantes, además de tener una impresionante memoria espacial, exhiben una actitud de duelo cuando uno de sus familiares fallece. Aves, como el pinzón, reacciona con su canto a las perturbaciones climáticas. Algunos animales no tienen reparos en adoptar incondicionalmente crías de especies que podrían potencialmente ser su depredador. Las abejas o las hormigas se organizan repartiendo diversas tareas y cuidando de su comunidad. ¿Podemos decir que en sus actos no hay una percepción, aunque sea probablemente inconsciente, de una trascendencia del yo individual hacia una intuición comunitaria? No todo acto animal es sólo instinto de supervivencia. Que la empatía sea más racional y menos instintiva, ¿implica que los humanos somos merecedores de la categoría de ciudadanos y no ellos, los animales? Son preguntas que precisan de una continuada reflexión.

Por su parte, Sue Donaldson y Will Kymlicka, en Zoópolis, también insisten en que hay que comprender las relaciones entre humanos y animales en términos explícitamente políticos y no sólo desde la ética aplicada ${ }^{15}$. Para ello, se centran en la idea de la ciudadanía, puesto que ésta permite asignar los derechos no sólo en virtud de la categoría de persona (moral), sino también según la organización política. Es decir, el hecho de ser persona o no, puede desembocar en el reconocimiento de unos derechos u otros, pero tal cualidad no tiene por qué afectar a aquellos derechos predicados de la condición de ser un ciudadano, que se repartirán según otras circunstancias variables. Es desde esta visión política a la que apela la ciudadanía que pongo sobre la mesa y abre la posibilidad de una fraternidad con los animales.

A mucha gente le cuesta considerar ciudadanos a los animales porque en la idea de ciudadanía suelen ver como intrínsecas múltiples acciones de participación política. Los animales no votan, no entablan debates públicos ni tampoco se movilizan políticamente por cuestionar unas decisiones públicas, en la línea argumentada por Bob Torres de que hay una

14 Rowlands, M. (2009), El Filósofo y el lobo, Barcelona: Seix Barral.

15 Donaldson, S. y Kymlicka, W. (2018), Zoópolis, Madrid: Errata Naturae, pp. 33-34. 
ausencia de agencia. Pero más allá de discutir sobre la disposición activa o no de agencia, Donaldson y Kymlicka desplazan la discusión hacia otros derroteros, aclarando que las ideas de participación política activa son sólo un aspecto de la ciudadanía ${ }^{16}$. Como apuntan, parte del problema deriva en la reducción de la teoría política a una sola dimensión de la misma: la actividad política democrática. Los animales no pueden aportar razones que se sometan a un consenso entrecruzado deliberativo, una condición esencial para la construcción de la democracia según autores de referencia, como John Rawls o Jürgen Habermas. ¿Pero acaso pueden los niños o la gente con demencia o discapacidades psíquicas graves? La resolución que dan los autores de Zoópolis es desplazar el foco que se centraliza en la agencia de una democracia política para atender a otras características cruciales de la ciudadanía, como son la nacionalidad o la soberanía popular. Para ellos, «la actividad política no es un umbral o criterio que determina quién es ciudadano; de forma que quienes no puedan ejercer tal o cual forma de actividad quedan relegados a un estatus de no ciudadanos» ${ }^{17}$.

Anita Silvers y Leslie Francis han propuesto diseñar nuevos modelos de actividad dependiente para los ciudadanos incapaces de comunicarse con una voz política. El objetivo de éstos consistiría en captar la percepción que tiene una persona de su bien subjetivo, expresado mediante una comunicación interiorizada en lugar de verbal. Entonces, los individuos incapaces de expresar racionalmente su preferencia precisarían de un colaborador que ayudase a construir una suerte de guión de sus conceptos de vida buena, basándose en la representación de imágenes, la emisión de sonidos, ciertos movimientos y reacciones como reír o llorar ${ }^{18}$. Todos pasamos por etapas de nuestra vida en las que necesitamos una actividad asistida de esa clase para poder formar parte, en sentido participativo, de la ciudadanía. El paso de la ética a la justicia con las personas en situación de dependencia supone ir más allá de cuidar de ellas e invitarlas a participar en el mundo de alguna manera, para que lo que tengan que decir influya también en las decisiones colectivas. La actividad política debería verse como algo inherente a una relación entre ciudadanos, no de forma independiente como atributo de los individuos que exista con anterioridad a la interacción de éstos.

Ahora bien, cabe matizar que para construir relaciones de actividad dependiente o asistida, se necesita un grado de intimidad y proximidad que tal vez no sea viable ni deseable en el caso de los animales salvajes. Pero no puede obviarse que incluso estos animales viven en relaciones complejas de interdependencia con los humanos que deberían regularse según unas normas de justicia. Pensemos, por ejemplo, en los numerosos mamíferos que se alimentan de unas determinadas plantas amenazadas por la lluvia ácida y en los peces asfixiados por la acumulación de aluminio en sus agallas. Pensemos en las tortugas y ballenas de los océanos cuyas vidas peligran por ingerir múltiples deshechos plásticos. ¿Y qué hay del gélido hábitat del oso polar cada vez más deteriorado por el cambio climático? Es realmente improbable que a día de hoy haya animales salvajes que vivan en territorios vírgenes a los que no haya llegado indirectamente la huella humana. Como afirma Gary Calore, la dominación de los seres humanos sobre el planeta ha demostrado que la individualidad y la independencia son estrategias evolutivas destinadas al fracaso y que nos aproximamos a

16 Donaldson, S. y Kymlicka, W., Zoópolis, p. 105, op. cit.

17 Donaldson, S. y Kymlicka, W., Zoópolis, p. 111, op. cit.

18 Silvers, A. y Francis, L. (2005), «Justice through Trust: Disability and the "Outlier Problem" in Social Contract Theory», Ethics, 116, pp. 40-76. 
una «época de formas interdependientes» ${ }^{19}$. Esto implica no dejar excluidos los derechos de los animales salvajes de la preocupación de una justicia internacional, dado que sus formas de vida, inevitablemente, coexisten con las nuestras en un mundo común.

Cabe matizar que para el derecho vigente de nuestro país, en especial el artículo 610 de nuestro Código Civil, los animales son simplemente cosas, con dueño o momentáneamente sin él: bienes objeto de apropiación. Igual que en momentos históricos anteriores los esclavos eran la propiedad de sus amos o las mujeres la propiedad de sus padres o esposos, hoy los animales son propiedad de ciertos sujetos de derecho en las formas que determina el derecho civil. Y por lo que respecta a los animales salvajes, mientras se encuentran en libertad son cosas sin dueño objeto de ocupación. Vivimos en una sociedad en el que la legislación considera que una persona jurídica puede ser una entidad, una fundación o una empresa, pero que un animal sólo es una cosa, un mero objeto corpóreo. Habrá quien aducirá que «lo característico de tener un derecho es que la persona que lo tiene lo puede reclamar» ${ }^{20}$, es decir, que tenga una cierta voz política. Pero autores como Hans Kelsen, ya han explicado que lo esencial de un derecho no es que su mismo titular pueda reclamarlo, sino que algún sujeto jurídico con capacidad de obrar (que no tiene por qué ser necesariamente el mismo titular) pueda reclamarlo en beneficio del titular. Del mismo modo, afirma Feinberg:

«Sencillamente no es cierto (...) que la capacidad de entender lo que es un derecho y la capacidad de poner en marcha la maquinaria legal por iniciativa propia sean necesarias para la titularidad de un derecho. Si ése fuera el caso, ni los retrasados mentales ni los bebés humanos tendrían derechos en absoluto. (...) Los niños y los retrasados mentales inician acciones jurídicas no por iniciativa propia, sino a través de las acciones de representantes legales que están apoderados para hablar en su nombre. Si semejante situación no encierra ningún absurdo conceptual, ¿por qué lo habría en

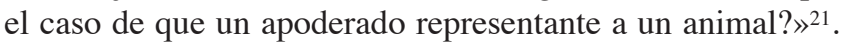

\section{La interdependencia invisible de los animales}

Más allá de la cohabitación de un espacio común, existen más razones para sustentar la idea de una fraternidad política entre humanos y animales no humanos. La pólis, como se ha comentado, es el espacio donde compartimos recursos, ejercemos la funciones vitales básicas, especialmente nos relacionamos estableciendo contactos (directos o indirectos) $\mathrm{y}$, en definitiva, donde todos vivimos sobre una misma tierra y bajo un mismo cielo. Esta consideración nos permite pensar acerca de una zoopolis. Pero en esta dimensión territorial no hay fenómenos estáticos, inmutables y permanentes, sino que acontecen constantes procesos dinámicos. La interrelación que se muestra en el espacio común es cambiante, queda inmersa a su vez en una dimensión temporal. Este nuevo vector posibilita los intercambios

19 Calore, G. (1999), «Evolutionary Covenants: Domestication, Wildlife and Animal Rights», en Cohn, P. (ed.), Ethics and Wildlife, Lewiston: Melleb Press, pp. 219-263.

20 Tugendhat, E. (1993), Justicia y derechos humanos, Barcelona: Publicacions Universitat de Barcelona, p. 15.

21 Citado de Riechmann, J. y Mosterín, J. (1995), Animales y ciudadanos, Madrid: Talasa, p. 214. Véase en particular Feinberg, J. (1980), «Human Duties and Animal Rights», en Rights, Justice and the Bounds of Liberty, Princeton: Princeton University Press. 
y la transformación de los fenómenos. Ello nos aproxima a una comprensión distinta de nuestra relación con el resto de seres vivos: si la zoopolis nos da a entender que compartimos el ambiente de un modo unidireccional, una ecopolis nos sugiere que las relaciones dentro de un entorno común se dan en múltiples direcciones. Por ejemplo, los plásticos abocados a los océanos y que son consumidos por las ballenas de mar adentro, no sólo ilustra daños lejanos de nuestros actos cotidianos y locales, como ya las éticas de la globalización tratan de explicar, sino que el proceso es más complejo: la asfixia de las ballenas reduce enormemente la cantidad de fitoplancton producido lo cual ralentiza la absorción de $\mathrm{CO}_{2}$ y favorece el cambio climático ${ }^{22}$. Como éste, existen numerosos ejemplos que evidencian la urgencia de entender la globalización de un modo interdependiente entre distintas especies y no como si las vidas de los animales importasen simplemente en tanto receptores de nuestras acciones globales. Lo que hagan con sus vidas o lo que les ocurra, también nos afectará a nosotros. En un sentido bastante literal, nuestra vida es su vida, y viceversa. La relación horizontal que mantenemos deja de trazar un límite de alteridad marcado por nuestros cuerpos físicos, para desdibujar dicho límite del organismo individual, dado que compartimos nuestras vidas con una profundidad ecológica que suele pasarnos inadvertida.

Francis Bacon fue uno de los pioneros en impulsar el proyecto ilustrado a partir del cual la razón descomponía las formas de vida con tal de analizarlas, clasificarlas y dominarlas en busca de verdades inductivas. Una metodología que no ha hecho sino fomentar el pensamiento dualista, conquistador y patriarcal en Occidente ${ }^{23}$, siguiendo la línea cartesiana, donde todo aquello situado más allá del propio cogito se objetiva y reduce. Sin embargo, esta forma de pensar empezó a virar en los años sesenta con el desarrollo de planteamientos que configuraban una revolución holística en la manera de ver la vida ${ }^{24}$. La hegemonía del reduccionismo y de la especialización predominante de la Época Moderna y de la Ilustración quedaría debilitada por los numerosos estudios que encuentran en la interdependencia la clave ontológica. José Ferrater Mora ya advirtió agudamente esta concatenación sistémica entre el individuo y la realidad al proponer su método integracionista ${ }^{25}$. Todos estos son enfoques que desde la década de los noventa la ciencia ecológica ha corroborado con el descubrimiento de las cascadas tróficas. Desde la ecología ya no se explica todo desde una perspectiva bottom-up, en la que las partes concretas (y bajas de la cadena trófica) se hallan separadas, sino que el top-down nos revela la conexión que se aprecia entre todo ser vivo (desde lo alto de la cadena trófica).

Cuando respiramos aire no inhalamos oxígeno porque nuestra capacidad racional así lo merezca, sino que es resultado de la actividad fotosintética de bacterias, algas y de plantas a lo largo de millones de años. Y que la cantidad de fitoplancton y de plantas sea el adecuado para asegurar un ambiente estable y favorable para nuestra existencia estable no es debido a una causa ajena a los millones de animales que existen en el planeta. Las cascadas tróficas producidas por una relación de top-down entre los seres vivos, configuran ecosistemas, diseñan geografías y habilitan climas específicos ${ }^{26}$.

22 Monbiot, G. (2017), Salvaje. Madrid: Capitán Swing.

23 Shiva, V. (1995), Abrazar la vida, Madrid: Horas y Horas, pp. 46-54.

24 Canadell, À. y Vicens, J. (2004), La textura de la vida, Barcelona: Documenta Universitaria, p. 76.

25 Ferrater, J. (1979), De la materia a la razón, Madrid: Alianza.

26 Terborgh, J. \& Estes, J. A. (ed.). (2010), Tophic cascades. Predators, prey and the changing dynamics of nature, Washington DC: Island Press. 
Leonardo Boff sintetiza cinco maneras de encadenar y relacionar las realidades del universo entre sí, cinco lógicas que conciben el mundo según: la identidad, la diferencia, la dialéctica, la reciprocidad, la pericorética. Esta última, la pericorética, remite a la expresión griega de circularidad e inclusión de todas las relaciones y de todos los seres relacionados ${ }^{27}$. Es la más compleja, pues no excluye lo coyuntural, el tiempo o las contingencias pasajeras, y va en contra de las clásicas inferencias científicas de reducir ordenada y linealmente hacia lo simple. Es una epistemología que pone en juego en todo momento y en todas direcciones el diálogo entre identidad y diferencia, por lo que la interculturalidad se manifiesta en un proceso de constante relación. Lo que Tomás de Aquino definiría como estar sentados en un mismo sitio, insistiendo en «la existencia de unos en otros» 28 .

En este sentido, el otro no es ya plenamente un ente separado biológicamente de nosotros, pero con quien nos podemos encontrar, empatizar, compartir los recursos del entorno y entablar una relación permeada por la cultura pero orgánicamente distanciada. El otro es un ente que, de algún modo, está orgánicamente fuera y dentro de nosotros. Aquí la diferenciación humano-animal pasa a ser todavía más irrelevante. La fórmula «yo soy, si tú eres», también trabajada por Franz Hinkelammert, nos indica que el sujeto no aparece en el cálculo de los intereses egoístas en el mundo de la mercancía, sino en la afirmación de la ecodependencia del ser humano: el tú de la fórmula puede ser tanto el otro humano como el otro animal y la naturaleza en su conjunto.

«La misma autorrealización como sujetos nos compromete ahora con la responsabilidad por el globo, es decir, se trata de una responsabilidad global. La otra cara de la autorrealización resulta ser la afirmación del otro, e incluida en él, también la de la naturaleza. No podemos asegurar nuestra vida destruyendo la vida del otro. Tenemos que afirmar también la vida del otro.

[...]El ser humano está involucrado en esta realidad porque su vida depende de ella. Si esta realidad se hunde, también el ser humano se hunde. El ser humano vive en una autopoiesis con la realidad externa, como la llama Humberto Maturana» ${ }^{29}$.

La manera de relacionarnos con el entorno varía según si la perspectiva reduce el conjunto de un sistema a sus componentes básicos o si, por contra, resalta las propiedades emergentes del sistema. Si consideramos las otras formas de vida como un recurso que podemos tratar como mercaderías explotables, en lugar de como partes de una trama interconectada de la que dependemos, la ética y la política irán en consonancia en sus argumentos. Pero si asumimos una bioética y una biopolítica como disciplinas emergentes que afrontan más adecuadamente la fragilidad del estado de nuestras vidas, nos acercamos a la sensible idea que reconoce la interdependencia y no jerarquiza moral y políticamente con tanta sencillez a los individuos basándose en rasgos menos relevantes (como pudiera ser la condición de racionalidad kantiana). Ello no quiere decir que la razón humana no sea útil para construir una comunidad armónicamente sostenible; lo es, ya por el mero hecho de comprender racionalmente la convivencia ecodependiente que mantenemos con nuestro entorno. Lo que

27 Boff, L. (2002), Grito de la Tierra, Grito de los Pobres, Madrid: Trotta.

28 Aquino, T. (2010), Suma Teológica, I, cap. 42, Madrid: Biblioteca de Autores Cristianos, pp. 197-204.

29 Hinkelammert, F. (1998), El grito del sujeto. Costa Rica: Departamento Ecuménico de Investigaciones, p. 292. 
significa es que tal rasgo no es un motivo que justifique un espacio político privilegiado respecto al resto de seres vivos, es decir, una carta de derechos que proporcionalmente a nuestra capacidad de desarrollarnos y realizarnos sea superior a la de los animales no humanos. El término de proporcionalidad es un matiz importante, dado que para el florecimiento de nuestra especie tal vez sea fundamental, por ejemplo, suscribir el derecho a practicar el culto religioso que prefiramos ${ }^{30}$, el derecho al voto o a la enseñanza, pero semejantes derechos no realzan ninguna capacidad básica de otras especies animales. El tipo de derechos que pueden conferirse a un posible titular depende de las características efectivas que tal criatura posea. Es arduo precisar qué derechos necesita cada especie para su plena realización y, por ende, desde la legislación política, habrán de reconocerse. Cada forma de vida vive su propia individualidad, y por tanto la filosofía moral y la filosofía política requieren del diálogo con biólogos, ecologistas, etólogos y otros expertos para crear un consenso interdisciplinar que sea justo con las capacidades de todas las especies. Este sería un gran paso hacia una justicia interespecífica.

Es un paso, no obstante, que no viene solo. Para ello de partida necesita del apoyo de una serie de derechos compartidos más elementales, como es el de fraternidad entre todas las especies, pues éste nos lleva a preocuparnos por la realización particular de sus vidas mediante el reconocimiento de los otros como hermanos.

En el presente trabajo, más allá de hacer pivotar los derechos animales en base a argumentos como la sintiencia individual ${ }^{31}$, el eje que impulsa la reflexión es la justicia relacional y la del reconocimiento. Los razonamientos que la sostienen no toman el interesante rumbo de indagar en nuestro parentesco genético, como ya han hecho otros autores ${ }^{32}$. Y no por evitar patinar ante la falacia naturalista, sino porque considero más urgente primar el debate en torno a las condiciones estructurales de convivencia, dado que en el espacio compartido y globalizado cada vez son mayores las capas de vulnerabilidad al ignorarse la interdependencia.

\section{La emancipación fraternal y el estructuralismo de la vulnerabilidad}

Entre los mismos que defienden unos derechos para los animales no hay univocidad a la hora de asumir que merecen un derecho político a la fraternidad. ¿Para qué ir tan lejos si a nivel conceptual podemos asegurar su bienestar mediante medidas como la compasión, la hospitalidad o la solidaridad? No cualquier persona se siente cómoda tratando al resto de seres humanos como hermanos, razón para no apoyar tampoco la fraternidad con los animales. ¿Acaso no basta con demostrar respeto o con otras formas distributivas o de reconocimiento que, aparentemente, imparten justicia?

30 Este es un ejemplo que James Rachels apunta mientras defiende la extensión del derecho a no ser torturado a toda especie sintiente. Véase Singer, P. y Regan, T. (1989), Animal Rights and Human Obligations, Englewood Cliffs: Prentice-Hall, p. 124.

31 Esta probablemente haya sido el punto de partida para reflexionar sobre los derechos de los animales que mayor popularidad ha obtenido las últimas décadas, gracias a los planteamientos de Peter Singer y Tom Regan, entre otros, inspirados por el utilitarismo benthamita.

32 Mosterín J. (2014), EL triunfo de la compasión, Barcelona: Alianza, pp. 84-88. 
A efectos prácticos, ciertamente lo que busca la fraternidad es el pleno respeto (predicado usualmente con derechos negativos) así como la voluntad de auxiliar y mejorar las condiciones de vida de los individuos, humanos o no, desfavorecidos o en peligro (con derechos positivos). Especialmente si la causa de tal vulnerabilidad es debida a la interacción humana. Y, en este sentido, el respeto o la solidaridad podrían parecer suficientes para garantizar una justicia interespecífica. Sin embargo, en ocasiones hace falta apuntar más alto para crear conciencia, motivar y movilizar hacia el cambio. La fraternidad política reclamada durante la Revolución francesa no es que en sí misma, literalmente, añadiese unos privilegios más ambiciosos que la plena libertad e igualdad política. Sino que sirvió como construcción simbólica que motivaría y empujaría hacia la esas libertades e igualdades que, en realidad, no se estaban haciendo efectivas. Más allá del sentido literal biológico de hermandad, el sentido metafórico añadió una visión que complementaría la aproximación por un mejor reconocimiento de derechos jurídicos para todos.

En concreto, sobre la alternativa de promover la hospitalidad antes que la fraternidad, es menester recordar que la noción de hospitalidad implica una relación donde un anfitrión invita, hospeda, a quien se haya fuera. Sin embargo, no se trata de que los animales estén plenamente fuera de nuestra casa, ya que los límites de la pólis son vagos por las razones que aquí se han esbozado y ello dificulta la exclusión tácita de una cierta ciudadanía compartida. Una relación de hospitalidad con los animales no se perturba ante una lógica separatista y fronteriza, sino que puede acomodarse ante fisuras estructurales que desplace el «nosotros» del «ellos».

Asimismo, en contraste con la solidaridad, la fraternidad tiene la ventaja de no conformarse con un trato supeditado al paternalismo entre un individuo superior que controla, en cierto sentido, la vida de otro inferior. La fraternidad brinda a cada uno la posibilidad de desarrollarse de acuerdo a su propia individualidad. En este sentido, Angel Puyol, sobre la distinción entre fraternidad y solidaridad dice:

«En cuanto a la solidaridad propiamente dicha, si bien es cierto que esta idea acoge con facilidad el sentido asistencial de la fraternidad, plasmado en el Estado de bienestar, se desentiende por completo de su sentido emancipador, esto es, de la lucha contra las múltiples formas sociales de exclusión, sumisión, arbitrariedad, discriminación y humillación.

Además, la fraternidad exige que los fraternos se traten entre sí como iguales, como iguales son las hermanas y hermanos de una misma familia, mientras que la solidaridad no se siente incómoda con relaciones asimétricas. Nos solidarizamos con los pobres del tercer mundo, con los desplazados por las guerras y con las ballenas en extinción, pero no cuestionamos la posición privilegiada o los mayores derechos de quienes ejercen la solidaridad $\gg^{33}$.

Entonces, la beneficencia de reducir nuestro trato a ser hospitalarios o solidarios con ellos, no evita la separación asimétrica que operan de fondo, así como tampoco empodera a los animales a través del reconocimiento de unos privilegios que deberían ser iguales a los

33 Puyol, A., El derecho a la fraternidad, p. 11, op. cit. 
nuestros. Parte de los argumentos usados por la ética de la compasión y la ética del cuidado, o por la solidaridad y el paternalismo en filosofía política, se sustentan sobre una concepción de la vulnerabilidad que dificulta afrontar adecuadamente el problema de la justicia.

La posibilidad de un derecho animal a ser tratado fraternalmente supera la interacción asistencial que reduce la vulnerabilidad a una cualidad individual en lugar de estructural. Igual que la ciudadanía no radica en una cualidad de la persona individualmente, sino en una condición del territorio y del entorno (así como de la relación que mantienen los seres vivos con éste), lo mismo ocurre con la vulnerabilidad. Y es que no debemos simplemente reconocer individuos o grupos vulnerables, sino las estructuras que los vulneran. Por ello, considero acertado el planteamiento de pensar en capas de vulnerabilidad ${ }^{34}$, puesto que supone un refinamiento de la bioética que va más allá de la simple etiqueta o corsé teórico. Es una metáfora que tiene en cuenta el dinamismo y la relacionalidad de los seres.

Así pues, la fraternidad no se entiende aquí como un reconocimiento entre individuos descontextualizados, con indiferencia del lugar en el que viven, in abstracto (como podría estipular un modelo contrafáctico rawlsiano). Se entiende, más bien, como un puente que une a los individuos bajo un espacio local. ¿Qué es este espacio que ha de reconocer la política para desarrollar su trato fraternal? La pólis, un entorno de ciudadanía. Ahora bien, ¿cómo es ésta? A día de hoy, con fronteras difusas debido a la interdependencia que ha propiciado la globalización y la fragilidad global ante los problemas ecológicos (presentes en todo el globo), nos encontramos ante un marco cosmopolita. Si la fraternidad desempeña su papel, como se ha dicho, entre aquellos que son considerados ciudadanos, que pertenecen a la (cosmo)pólis, ¿quién se beneficiará más del trato fraternal? Aquellos que cohabiten en la pólis pero bajo un manto de vulnerabilidad. No que sean vulnerables por sí solos, sino porque los actuales derechos de igualdad o libertad no les concedan una condición de vida suficiente para su florecimiento, para su emancipación. Aunque todos los seres humanos podemos considerarnos ciudadanos que precisan con cierta urgencia un trato fraternal dada la inestabilidad ecológica en la que vivimos y compartimos, especialmente aquí nos hemos centrado en los animales no humanos. Esto es porque ellos, a pesar de compartir con nosotros esa capa de vulnerabilidad ecológica e interdependencia (hecho que les hace pertenecientes a la misma comunidad política), sus derechos son escasamente reconocidos. Esto es porque ellos, aun siendo nuestros conciudadanos, son tratados como si su relación con el entorno fuera menos importante que la nuestra.

\section{Conclusión: ¿exigir fraternidad interespecífica es demasiado?}

En los años 50 Hannah Arendt ya afirmaba que la solidaridad de la humanidad podía terminar siendo un peso insoportable, de manera que un altruismo cósmico derivase en la apatía política, un nacionalismo partidario del aislamiento político o una rebelión desesperada contra todos los poderes ${ }^{35}$. En el presente, nuestras intervenciones sobre el medio afectan a la comunidad entera de vida sobre la tierra, lo cual exige una perspectiva universal

34 Luna, F. (2011), «Vulnerabilidad: un concepto muy útil. Abandonando los "corsets teóricos"», Revista Redbioética/UNESCO, año 2, vol. 2, nº 4, pp. 85-90.

35 Arendt, H. (1993), La condición humana, Barcelona: Paidós. 
de responsabilidad. Ulrich Beck ya ha sostenido que esta situación compartida de riesgo global trasciende el poder decisivo de los Estados nacionales e implica la supresión de las fronteras entre el hombre, la bestia y las plantas ${ }^{36}$. Esto puede llevar la comunidad de la Tierra postulada por Aldo Leopold a su actualización política y moral. Además, diversos autores expanden los deberes no sólo hacia los seres no humanos, sino también hacia las generaciones futuras, protegiendo así una justicia intergeneracional ${ }^{37}$.

¿Pero este deber universal no va en detrimento del objetivo propio del cosmopolitismo ecológico? Al no hallar fronteras que acoten nuestra responsabilidad, ¿una presunta fraternidad universal no resulta poco pragmática? Pensar que todo ser vivo (y aún por nacer) tiene unos derechos que debemos respetar, ¿no abruma nuestro sentido ético y hace infértil la legislación política? Es cierto que la aproximación a una justicia universal tal y como auguraba Arendt puede contraer una serie de lamentaciones y desmotivaciones empáticas dada la inmensa complejidad del contenido incluido en el círculo moral. Alasdair MacIntyre también ha argumentado desde el comunitarismo la imposibilidad efectiva de establecer un acuerdo universal ${ }^{38}$. Y hay filósofos, como Fernando Savater, que se han enrocado en el argumento de que dada nuestra capacidad racional de someter las pautas motivacionales o de conducta de forma pre-reflexiva a la crítica y la revisión, y crear nuevas formas de conducta, nos separa un abismo ontológico respecto al resto de especies que puede justificar un trato diferenciado ${ }^{39}$. Así, se preguntan: ¿por qué invertir esfuerzos y exigencias en otras especies cuando el ser humano ya padece suficientes injusticias merecedoras de atención?

Ante las críticas que sugieren sesgar derechos y deberes con pretensiones interespecíficos o universales, dadas las dificultades de aplicación efectiva, quiero concluir exponiendo tres breves razones de por qué pensar en pos de una fraternidad política que vaya más allá de nuestros allegados humanos no es una idea descabellada:

Primero, todos los derechos son prima facie. Esto implica que los derechos no suponen una igualdad efectiva y que, a la práctica, chocan constantemente entre sí. Pero la existencia de conflictos entre derechos no anula la importancia de los mismos a la hora de tratar injusticias ${ }^{40}$.

Segundo, la moral ha de ser elástica. La razón instrumental no es el único uso de la capacidad intelectiva del ser humano. Albergamos también la razón simbólica y cordial y el uso de todos nuestros sentidos corporales y espirituales. Como dice Leonardo Boff, «junto al logos (razón) está el eros (vida y pasión), el pathos (afectividad y sensibilidad) y el daimon (la voz interior de la naturaleza). Conocer no es sólo una forma de dominar la realidad. Conocer es entrar en comunión con las cosas ${ }^{41}$. Entonces, debería ser misión de la filosofía, del amor por el saber, esforzarse por extender el círculo de la moral.

Y tercero, es complicado, pero no imposible: hay estrategias para fomentar el contagio emocional, la empatía. Un contacto local que visibilizara las condiciones en las que se

36 Beck, U. (1998), La sociedad del riesgo, Barcelona: Paidós, p. 66.

37 Autores como Andrew Dobson, Edith Weiss, Bryan Norton, Jörg Tremmel y Jorge Riechmann, son algunas de las voces representativas en esta cuestión.

38 MacIntyre, A. (1987), Tras la virtud, Barcelona: Crítica.

39 Savater, F. (2011), Tauroética, Madrid: Turpial, p. 29.

40 Mosterín, J. y Riechmann, J., Animales y ciudadanos, p. 148, op. cit.

41 Boff, L., Grito de la Tierra, Grito de los Pobres, op. cit. 
encuentran los animales en laboratorios, granjas industriales o mataderos, por ejemplo, podría ser una manera de sensibilizarnos por los millones de individuos que son explotados sin que reciban el más mínimo tacto fraternal. En cuanto a los animales salvajes más alejados de los núcleos de nuestras ciudades, hay métodos que consisten en colocar cámaras u otros medios ocultos para detectarlos sin que se interfiera apenas en su estilo de vida. A partir de ahí, el aprendizaje por sus formas de desenvolverse en el mundo, la pura admiración estética de las distintas formas de vida, pueden inhibir un tanto el prejuicio antropocentrista.

\section{Referencias}

Aquino, T. (2010), Suma Teológica, I, Madrid: Biblioteca de Autores Cristianos.

Arendt, H. (1993), La condición humana, Barcelona: Paidós.

Aristóteles (2004), Política, Madrid: Tecnos.

Beck, U. (1998), La sociedad del riesgo, Barcelona: Paidós.

Bentham, J. (1982), An Introduction to the Principles of Morals and Legislation, London: Methuen.

Boff, L. (2002), Grito de la Tierra, Grito de los Pobres, Madrid: Trotta.

Calore, G. (1999), «Evolutionary Covenants: Domestication, Wildlife and Animal Rights», en Cohn, P. (ed.), Ethics and Wildlife, Lewiston: Melleb Press, pp. 219-263.

Canadell, À. y Vicens, J. (2004), La textura de la vida, Barcelona: Documenta Universitaria.

Domènech, A. (2004), El eclipse de la fraternidad, Barcelona: Crítica.

Donaldson, S. y Kymlicka, W. (2018), Zoópolis, Madrid: Errata Naturae.

Feinberg, J. (1980), «Human Duties and Animal Rights», en Rights, Justice and the Bounds of Liberty, Princeton: Princeton University Press.

Ferrater, J. (1979), De la materia a la razón, Madrid: Alianza.

Hinkelammert, F. (1998), El grito del sujeto. Costa Rica: Departamento Ecuménico de Investigaciones.

Hribal, J. (2014), Los animales son parte de la clase trabajadora, Madrid: Ochodoscuatro.

Luna, F. (2011), «Vulnerabilidad: un concepto muy útil. Abandonando los "corsets teóricos"», Revista Redbioética/UNESCO, año 2, vol. 2, n 4, pp. 85-90.

MacIntyre, A. (1987), Tras la virtud, Barcelona: Crítica.

Marx, K. (1990), Capital, Nueva York: Penguin Classics, vol. 1.

Monbiot, G. (2017), Salvaje. Madrid: Capitán Swing.

Mosterín, J. y Riechmann, J. (1995), Animales y ciudadanos, Madrid: Talasa.

Mosterín J. (2014), El triunfo de la compasión, Barcelona: Alianza.

Pelluchon, C. (2018), Manifiesto animalista. Politizar la causa animal, Barcelona: Reservoir Books.

Puyol, A. (2017), El derecho a la fraternidad, Madrid: Catarata.

Rowlands, M. (2009), El Filósofo y el lobo, Barcelona: Seix Barral.

Savater, F. (2011), Tauroética, Madrid: Turpial.

Shepard, P. (1997), The Others: How Animals Made us Human, Washington DC: Island Press.

Shiva, V. (1995), Abrazar la vida, Madrid: Horas y Horas. 
Silvers, A. y Francis, L. (2005), «Justice through Trust: Disability and the "Outlier Problem" in Social Contract Theory», Ethics, 116, pp. 40-76.

Singer, P. y Regan, T. (1989), Animal Rights and Human Obligations, Englewood Cliffs: Prentice-Hall.

Singer, P. (2011), Liberación animal, Madrid: Taurus.

Smith, A. (2011), La riqueza de las naciones, Madrid: Alianza.

Terborgh, J. \& Estes, J. A. (ed.). (2010), Tophic cascades. Predators, prey and the changing dynamics of nature, Washington DC: Island Press.

Tugendhat, E. (1993), Justicia y derechos humanos, Barcelona: Publicacions Universitat de Barcelona. 